\title{
Genetic Variation and Population Structure of Dendropanax morbifera Lev. (Araliaceae) in Korea
}

\author{
By S. H. KIM ${ }^{1, * *}$, Y. S. JANG ${ }^{1)}$, J. G. $\mathrm{HAN}^{1)}$, H. G. $\mathrm{CHUNG}^{1)}$, S.W. LeE ${ }^{1)}$ and K. J. CHO ${ }^{2)}$
}

(Received 15 ${ }^{\text {th }}$ March 2005)

\begin{abstract}
Dendropanax morbifera Lev. (Araliaceae) is an economically important tree species because of its role in the production of golden varnishes as well as its use as an ornamental plant. As an endemic tree species of Korea, it is restricted to the southern parts of Korea as isolated populations. In this study, eight natural populations of $D$. morbifera were investigated by starch-gel electrophoresis in an attempt to determine the extent of its genetic diversity. Out of 8 natural populations, the Suak population in Jeju island showed the lowest level of genetic diversity, while the Wando island population in Jeonnam showed the highest level of genetic diversity. Levels of genetic diversity maintained in $D$. morbifera $(A / L=1.5, \quad P 95=27.3 \%, \quad H o=0.100, \quad H e=0.095)$ were notably lower than those of other tree species with wider and more continuous geographic distributions. The reasons for the low level of genetic diversity in $D$. morbifera might be due to the genetic drift caused by artificial disturbances. Most of the total genetic diversity $(96 \%)$ was found within the populations. The UPGMA dendrogram based on Nei's genetic distance did not show any particular geographic patterns. The low level of genetic diversity suggested that there should be an urgent emphasis on the conservation study of this species.
\end{abstract}

Key words: Dendropanax morbifera, genetic variation, natural populations, isozymes.

\section{Introduction}

Dendropanax is a subtropical, broad-leaved evergreen tree belonging to the Aralia family. This Korean endemic tree species is limited in distribution ranging from Jeju island to Wando island and Haenam, in the southwestern coastal or island areas (KIM, 1998). Lacquer derived from Dendropanax has excellent clarity and polishing qualities. This natural varnish has a golden color that is considered to be an excellent varnish for use in woodworking and metalworking.

The importance of this craft is reflected the increasing living standard among the people in their increasing preference for high quality craft objects (KIM, 1998). Dendropanax has other potential products that need further development as commodities. Also, Dendropanax's value is being reconsidered both in terms as a specialty ornamental plant and in preserving its genetic

1) Division of Forest Genetic Resources, Korea Forest Research Institute, 44-3 Omokcheon, Suwon, Gyenoggi 441-350, The Republic of Korea.

${ }^{2}$ ) Department of Forest Resources, College of Agriculture and Life Science, Suncheon National University, 315 Maegok, Sunchoen, Jeonnam 540-742, The Republic of Korea.

*) To whom correspondence should be addressed: Tel: +82-31-2901190, Fax: +82-31-290-1050, email: goldtree@foa.go.kr resources. However, the study of useful genetic variation and diversity to its basic materials has not been made.

In order to develop the characteristic form and quality of Dendropanax, we have to understand, maintain and preserve the forest populations, which has a varied genetic variation. To do this, we have to precede such selection and maintenance with an analysis of the genetic variation of this forest tree as it is naturally distributed (HAMRICK et al., 1979; LOVELESS and HAMRICK, 1984). Generally, plant's genetic variation is exclusively distributed on the level of the corresponding enzyme that is long in longevity, and the allogamy plants compared to non-allogamy plants are well known to have variety in the area of genetic variation. Species of trees like Dendropanax, which have a limited distribution, or the plants that are rare or extinct, are considered to have limited genetic variation through genetic disorders or near-relative mating compared to the species of trees which are distributed exclusively and continually (LEDIG and Conkle, 1983; WALler et al., 1987; LESICA et al., 1988; LEE et al., 1997; LEE et al., 1998; KIM, 1998).

This study, which is relative to the region of the natural distribution of Dendropanax, through the analysis of corresponding enzymes, clarifies the characteristics of the genetic diversity in the Dendropanax's natural population and supplies the fundamental data for growing it, as well as for preserving its genetic resources. Also, the results of this study can be used to provide important fundamental or basic data when we compare and examine the genetic features of this subtropical broad-leaved evergreen tree that is native to Korea.

\section{Materials and Methods \\ Official material}

The specimens were selected from eight wild populations located in Donghong, Sanghyo, Suak, Sundol, and Youngbul in Jeju Island and Haenam, Bogildo island and Wando island in Jeonnam (Figure 1).

Also, the distance between selected objects was set at more than $50 \mathrm{~m}$ in order to avoid tree objects that were common lineage. In order to analyze genetic variation of Dendropanax, we used the new leaves gratuitous treatment for analyzing the corresponding enzyme from a selected population of 30 specimen trees. The fresh leaves were immediately placed in plastic bags and were refrigerated at a temperature of $4{ }^{\circ} \mathrm{C}$ until the experiment was carried out.

\section{Enzyme analysis}

When we analyzed the corresponding enzyme, we made a buffer liquid and used the method of KIM et al. 


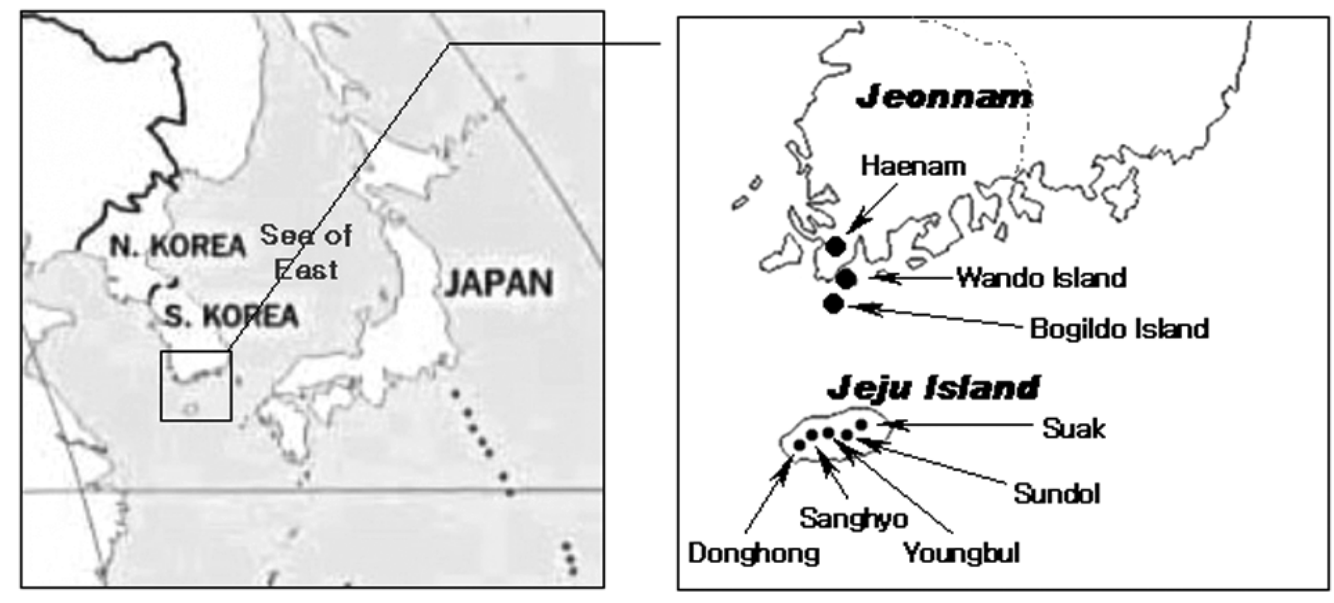

Figure 1. - Location map of 8 D. morbifera populations in Korea that were sampled for isozyme analysis.

(1993). Electrophoresis was performed using $12 \%$ starch gel. The gel was finished with electrophoresis and cut horizontally. A chemical reaction was made with each corresponding enzyme and we surveyed the eleven enzymes; aconitase (ACO, E.C. 4.2.1.3), glutamate dehydrogenase (GDH, E.C. 1.4.1.3), glutamate-oxaloacetate transaminase (GOT, E.C. 2.6.1.1), isocitric dehydrogenase (IDH, E.C. 1.1.1.42), leucine aminopeptidase (LAP, E.C. 3.4.11.1), menadion reductase (MNR, E.C. 1.6.49.2), malate dehydrogenase (MDH, E.C. 1.1.1.37), 6-phosphogluconate dehydrogenase (6PGD, E.C. 1.1.1.44), phosphoglucose isomerase (PGI, E.C. 6.3.1.9), phosphoglucomutase (PGM, E.C. 2.7.5.1), and shinkimate dehydrogenase (SKDH, E.C. 1.1.1.25).

\section{Data analysis}

We excluded ACO, GDH, LAP, MNR, PGM, and SKDH from the genetic analysis, because they are inert, or if there are some amounts present, they are extremely unclear or unstable. Of the eleven enzymes used in analyzing the data, we examined and analyzed the pattern of inheritance of five enzymes (GOT, IDH, MDH, 6PGD, PGI) and eleven loci (Got-1, Got-2, Idh-1, Idh-2, Mdh-1, Mdh-2, 6Pgd-1, 6pgd-2, Pgi-1, Pgi-2, Pgi-3). We cannot determine the pattern of inheritance in each corresponding enzyme, because the trees were not artificially mated progeny, however, we can indirectly assume it considering the reported data from other similar plants and as a function of the enzyme and biochemical structure (WEEDEN and WENDAL, 1989). From each hereditary position, we determine the observed value of heterozygosity $(\mathrm{Ho})$ and the expected value of average heterozygosity $(\mathrm{He})$ based on the frequency $(A / L)$ of the form of inheritance in each sample, and we judged if the examined hereditary frequency $(P)$ coincides with the HardyWeinberg parallel frequency according to the $X^{2}$ test by Levene's correction (1949). A locus was considered polymorphic when more than one allele were detected, regardless of their frequencies. Therefore, we can combine and analyze the form of heredity, which has lower frequency (SoKAL and RoHLF, 1981). At the same time, we do the exact-test by Fisher (CHAPCO, 1976), and we regard it as separation from Hardy-Weinberg paral- lelism when there is any similarity in statistics, both the $X^{2}$ test and the exact-test. The genetic structure both within and among populations was evaluated using Wright's F-statistics (1978); $F_{I S}, F_{I T}$, and $F_{S T}$ after we have genetic distance by NEI (1978), and we do the test of cluster analysis by the method of UPGMA (SNEATH and SoKAL, 1973). Above all, in the analysis, we use BIOSYS-1 (SwOFForD and SElANDER, 1989) that is a program for the use of a PC.

\section{Results}

\section{Allele frequency and distribution}

Table 1 shows the allele frequencies and distribution of the eleven genetic loci, such as; Got-1, Got-2, Idh-1, Idh-2, Mdh-1, Mdh-2, 6Pgd-1, 6Pgd-2, Pgi-1, Pgi-2, and $P g i-3$. Among the eleven genetic loci analyzed, from Got2, Idh-1, Idh-2, 6Pgd-1, and Pgi-1, we can find only one allele. We cannot find any diversity from Got-1, Mdh-1, Mdh-2, 6Pgd-2, Pgi-2, and Pgi-3, and two to four genetic loci can be seen.

For genetic loci having multi-forms, the same allele is the main allele. From Pgi-3, according to the populations the main allele frequency is more or less different: the allele c shows that the frequency is 0.05 in the Wando island population only and indicates a unique allele in the populations. However, in terms of the low frequency, it is probably a result of the process of specimen sampling. In other words, if we increase the number of specimens or choose another method of specimen sampling, we can better estimate the possibility of preservation. However, the frequency has nothing to do with the adjustment feature in the populations, so we will continue to examine the frequency in detail.

\section{Genetic variation}

Table 2 shows the result of genetic variation of Dendropanax. The number of average alleles in each genetic locus ranges from 1.4 (Haenam and Suak populations) to 1.7 (Wando island population), and on mean is 1.5. On the level of $95 \%$, the rate of multi-forming genetic locus indicates that Bogildo island and Suak populations evaluate at $18.2 \%$, which is the lowest. The Sanghyo and 
Wando island populations are $36.4 \%$, which is the highest, and their mean is $27.3 \%$. On the level of $99 \%$, the rate of multi-forming genetic position shows that the Suak population is $18.2 \%$, which is the lowest, and the Wando island population is $45.5 \%$, which is the highest, and the mean is $30.7 \%$.

The average observed variation number of heterozygosity $(\mathrm{Ho})$ shows that the Sundol population is 0.075 , which is the lowest. The Sanghyo is 0.123 , which is the highest, and the mean of the whole population is 0.1 .
The average expected number of heterozygosity $(\mathrm{He})$ indicates that the Suak and Sundol populations are 0.075 , which is the lowest. Wando island population is 0.123 , which is the highest, and the mean of the whole population is 0.095 . From these results, we can estimate the Suak population has less genetic diversity than the others. The Wando island population has a more or less various genetic diversity. HAMRICK et al. (1992) compared genetic diversity of many plants on the level of the same locus enzyme and reported that the amount

Table 1. - Allele frequencies for 6 polymorphic loci in 8 populations of D. morbifera in Korea.

\begin{tabular}{|c|c|c|c|c|c|c|c|c|}
\hline \multirow[b]{2}{*}{ Locus } & \multicolumn{8}{|c|}{ Population } \\
\hline & $\begin{array}{c}\text { Bogildo } \\
\text { island } \\
(29.5)\end{array}$ & $\begin{array}{c}\text { Donghong } \\
\text { (28.5) }\end{array}$ & $\begin{array}{c}\text { Haenam } \\
(29.6)\end{array}$ & $\begin{array}{c}\text { Sanghyo } \\
\text { (29.8) }\end{array}$ & $\begin{array}{c}\text { Suak } \\
(29.4)\end{array}$ & $\begin{array}{c}\text { Sundol } \\
(29.3)\end{array}$ & $\begin{array}{l}\text { Wando } \\
\text { island } \\
(29.7)\end{array}$ & $\begin{array}{c}\text { Youngbul } \\
(29.6)^{1)}\end{array}$ \\
\hline Got-1 a & .396 & .267 & .135 & .304 & .333 & .227 & .315 & .269 \\
\hline$b$ & .146 & .200 & .250 & .071 & .104 & .114 & .130 & .192 \\
\hline $\mathrm{c}$ & .147 & .467 & .615 & .571 & .500 & .614 & .500 & .519 \\
\hline $\mathrm{d}$ & .042 & .067 & .000 & .054 & .063 & .045 & .056 & .019 \\
\hline Got-2 a & 1.000 & 1.000 & 1.000 & 1.000 & 1.000 & 1.000 & 1.000 & 1.000 \\
\hline $\mathrm{b}$ & .000 & .000 & .000 & .000 & .000 & .000 & .000 & .000 \\
\hline$I d h-1 \mathrm{a}$ & 1.000 & 1.000 & 1.000 & 1.000 & 1.000 & 1.000 & 1.000 & 1.000 \\
\hline $\mathrm{b}$ & .000 & .000 & .000 & .000 & .000 & .000 & .000 & .000 \\
\hline$I d h-2 \mathrm{a}$ & 1.000 & 1.000 & 1.000 & 1.000 & 1.000 & 1.000 & 1.000 & 1.000 \\
\hline $\mathrm{b}$ & .000 & .000 & .000 & .000 & .000 & .000 & .000 & .000 \\
\hline$M d h-1 \mathrm{a}$ & .000 & .000 & .000 & .050 & .000 & .050 & .183 & .000 \\
\hline $\mathrm{b}$ & 1.000 & 1.000 & 1.000 & .950 & 1.000 & .950 & .817 & 1.000 \\
\hline$M d h-2$ a & .950 & .917 & .900 & .850 & .900 & .917 & .917 & .850 \\
\hline $\mathrm{b}$ & .050 & .083 & .100 & .150 & .100 & .083 & .083 & .150 \\
\hline $6 p g d-1$ a & 1.000 & 1.000 & 1.000 & 1.000 & 1.000 & 1.000 & 1.000 & 1.000 \\
\hline $\mathrm{b}$ & .000 & .000 & .000 & .000 & .000 & .000 & .000 & .000 \\
\hline $6 p g d-2$ a & .967 & 1.000 & 1.000 & 1.000 & 1.000 & 1.000 & 1.000 & 1.000 \\
\hline$b$ & .033 & .000 & .000 & .000 & .000 & .000 & .000 & .000 \\
\hline$P g i-1$ a & 1.000 & 1.000 & 1.000 & 1.000 & 1.000 & 1.000 & 1.000 & 1.000 \\
\hline$b$ & .000 & .000 & .000 & .000 & .000 & .000 & .000 & .000 \\
\hline$P g i-2$ a & .000 & .000 & .000 & .000 & .000 & .000 & .033 & .000 \\
\hline b & 1.000 & 1.000 & 1.000 & 1.000 & 1.000 & 1.000 & .967 & 1.000 \\
\hline$P g i-3$ a & .033 & .172 & .067 & .167 & .000 & .000 & .050 & .250 \\
\hline $\mathrm{b}$ & .967 & .828 & .933 & .833 & 1.000 & 1.000 & .900 & .750 \\
\hline $\mathrm{c}$ & .000 & .000 & .000 & .000 & .000 & .000 & .050 & .000 \\
\hline
\end{tabular}

${ }^{1)}$ Mean number of trees per locus. 
Table 2. - Genetic diversity estimates for 8 populations of D. morbifera in Korea.

\begin{tabular}{|c|c|c|c|c|c|}
\hline Populations & $A e$ & P95 & P99 & Ho & $\mathrm{He}$ \\
\hline Bogildo island & $\begin{array}{l}1.5 \\
(.3)\end{array}$ & 18.2 & 36.4 & $\begin{array}{c}.112 \\
(.089)\end{array}$ & $\begin{array}{c}.081 \\
(.059)\end{array}$ \\
\hline Donghong & $\begin{array}{l}1.5 \\
(.3)\end{array}$ & 27.3 & 27.3 & $\begin{array}{c}.095 \\
(.062)\end{array}$ & $\begin{array}{c}.103 \\
(.065)\end{array}$ \\
\hline Haenam & $\begin{array}{l}1.4 \\
(.2)\end{array}$ & 27.3 & 27.3 & $\begin{array}{c}.087 \\
(.063)\end{array}$ & $\begin{array}{c}.078 \\
(.051)\end{array}$ \\
\hline Sanghyo & $\begin{array}{l}1.5 \\
(.3)\end{array}$ & 36.4 & 36.4 & $\begin{array}{c}.123 \\
(.070)\end{array}$ & $\begin{array}{c}.111 \\
(.057)\end{array}$ \\
\hline Suak & $\begin{array}{c}1.4 \\
(1.3)\end{array}$ & 18.2 & 18.2 & $\begin{array}{c}.090 \\
(.072)\end{array}$ & $\begin{array}{c}.075 \\
(.059)\end{array}$ \\
\hline Sundol & $\begin{array}{l}1.5 \\
(.3)\end{array}$ & 27.3 & 27.3 & $\begin{array}{c}.075 \\
(.054)\end{array}$ & $\begin{array}{c}.075 \\
(.052)\end{array}$ \\
\hline Wando island & $\begin{array}{l}1.7 \\
(.3)\end{array}$ & 36.4 & 45.5 & $\begin{array}{c}.100 \\
(.059)\end{array}$ & $\begin{array}{c}.123 \\
(.060)\end{array}$ \\
\hline Youngbul & $\begin{array}{l}1.5 \\
(.3)\end{array}$ & 27.3 & 27.3 & $\begin{array}{c}.116 \\
(.062)\end{array}$ & $\begin{array}{c}.116 \\
(.065)\end{array}$ \\
\hline Mean & 1.5 & 27.3 & 30.7 & .100 & .095 \\
\hline
\end{tabular}

* Ae, the effective number of alleles per locus; $P 95, P 99$ percent of polymorphic loci at $95 \%$ and $99 \%$ criterion, respectively; $\mathrm{Ho}$, the observed heterozygosity; $\mathrm{He}$, the heterozygosity expected under Hardy-Weinberg; Standard errors are express in parentheses.

and distribution of genetic diversity for one plant species is influenced by the biological and life historical feature, and the amount and structure of genetic diversity which has a similar biological and life historical feature, has a great similarity.

\section{Wright's $F$ analysis}

Table 3 shows the result from $\mathrm{F}$ analysis of WRIGHT (1978). The value of $F_{I S}$ shows the degree of near-relationship mating within the same population. If the value is zero, it means a Hardy-Weinberg parallelism state, when $F_{I S}$ value is negative, the heterozygote frequency is higher than the Hardy-Weinberg parallelism frequency. If the value of $F_{I T}$ is regarded as whole populations are examined as one population, the whole genetic frequency has the same genetic structure compared to Hardy-Weinberg parallelism frequency and it has the same interpretation as $F_{I S}$ among the multiform six genetic loci examined. Four of them have the value of a negative number, two have a positive number $\left(F_{I S}\right)$, and the whole mean value is considered -0.072 , which means a higher heterozygote frequency compared to the Hardy-Weinberg parallelism frequency. The value of $F_{I T}$ also similarly to $F_{I S}$ has a negative value in four
Table 3. - Wright's F-statistics for polymorphic loci for 8 populations of D. morbifera in Korea.

\begin{tabular}{cccc}
\hline Loci & $F_{\text {IS }}$ & $F_{\text {IT }}$ & $F_{S T}$ \\
\hline Got-1 & -.172 & -.147 & .021 \\
Mdh-1 & .387 & .451 & .105 \\
Mdh-2 & -.124 & -.111 & .012 \\
6pgd-2 & -.034 & -.004 & .029 \\
$P g i-2$ & -.034 & -.004 & .029 \\
Pgi -3 & .182 & .250 & .084 \\
Mean & -.072 & -.0345 & .035 \\
\hline
\end{tabular}

${ }^{*} F_{I S}$ and $F_{I T}$, deviations of genotype frequencies from HardyWeinberg expectations within each population and over all populations, respectively; $F_{S T}$, population of the total genetic diversity partitions among population. 
genetic loci and has a positive value in two genetic loci, while the average value over the six genetic loci means more or less higher heterozygote frequency compared to the Hardy-Weinberg parallelism frequency.

From the values of $F_{I S}$ or $F_{I T}$, we can estimate that genetic firm through the differentiation and artificial destruction of Dendropanax. The genetic diversity greatly decreased, in some populations near the quite small number of aged trees, similar in level to a secondary growth forest, as distributed, single trees consisting of the stand are near in terms of blood relationship. We should in a future detailed study compare the genetic structure of mature trees and their progeny, along with mating pattern and the characteristic of reproduction. Meanwhile, about $96 \%$ of the whole genetic diversity caused by the difference of objects between groups and the degree of the populations' differentiation doesn't have a gap $\left(F_{S T}=0.035\right)$. This result shows that because Dendropanax is distributed with discontinuity and the population appears only as a part, we expected the differentiation between populations to be more or less significant, but the degree of differentiation to not be significant. This result comes from the fact that because birds carry out the seed distribution of Dendropanax, genetic interchange during the long period is complicated. However, because we studied only six genetic loci that are multi-form, we need to conduct a major study in detail over more genetic loci.

\section{Genetic distance and Cluster analysis}

Table 4 shows the result of Nei's (1978) genetic distance. The genetic distance of Bogildo island, Donghong, Sanghyo, Suak, and Youngbul populations range from 0.00 to 0.006 , and the Donghong and Sanghyo populations indicate that same populations. The Sundol and Youngbul result is 0.006 , which is the highest, but in general, is similar to the $F_{S T}$ analysis and has little degree of genetic differentiation inter-populations.

Figure 2 shows the result of cluster analysis by the UPGMA method through using genetic distance. The results showed that the eight populations are divided into two populations: the Donghong and Youngbul populations consisted of one small group related to the Sanghyo population, and also, the Bogildo island and
Suak populations are related to each other. Those are related to the groups consisting of the Haenam populations and the Sundol populations.

The populations of Dendropanax seem to belong to the same populations are close geographically. However, the Dendropanax population which are near geographically as the same populations, versus the population which is far geographically, is likely to be the same group, but there is not any sign of definite geographically difference. As we have seen before, we can assume the fact that there is no definite geographically difference, not only because after the third period, the reason for the

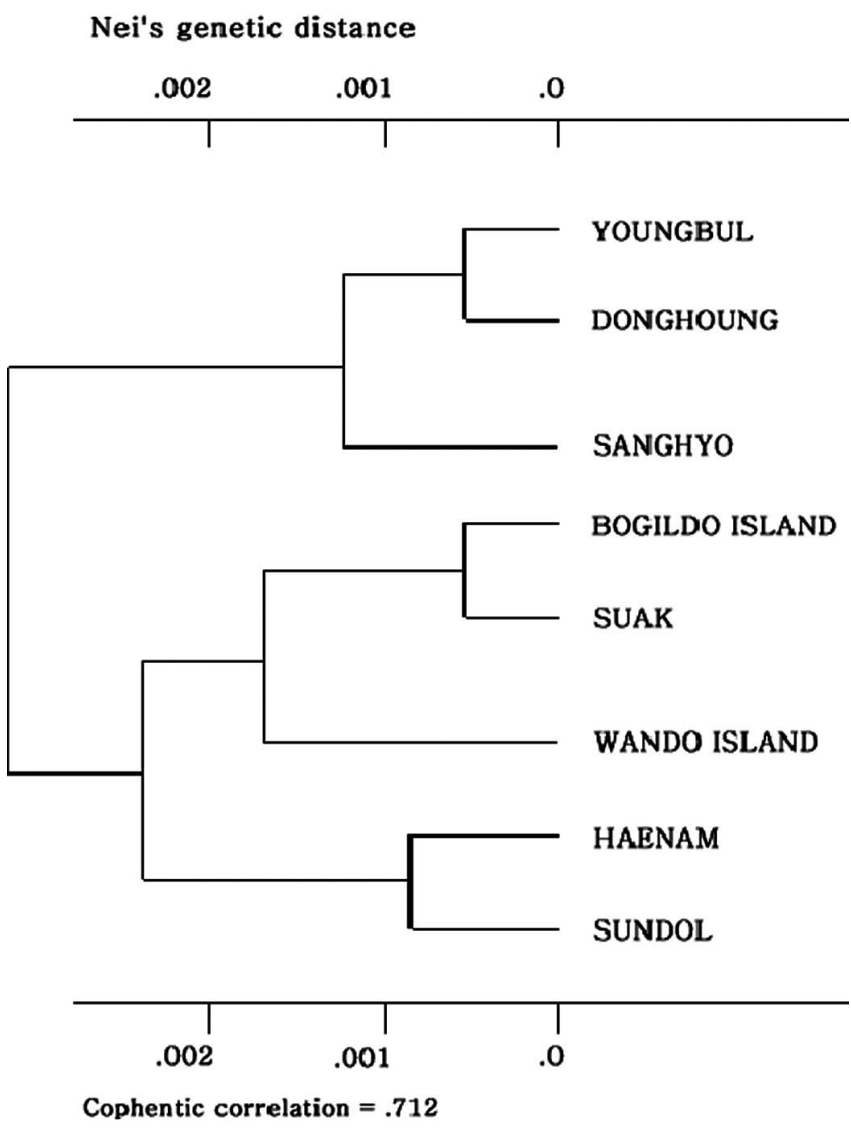

Figure 2. - Dendrogram showing the clustering of the 8 natural populations of $D$. morbifera based on Nei's genetic distance coefficient.

Table 4. - Nei's (1978) unbiased distance estimate among 8 populations of D. morbifera in Korea.

\begin{tabular}{ccccccccc}
\hline Populations & $\begin{array}{c}\text { Bogildo } \\
\text { island }\end{array}$ & Donghong & Haenam & Sanghyo & Suak & Sundol & $\begin{array}{c}\text { Wando } \\
\text { island }\end{array}$ & Youngbul \\
\hline $\begin{array}{c}\text { Bogildo } \\
\text { island }\end{array}$ & $* * * *$ & .001 & .005 & .003 & .000 & .002 & .002 & .005 \\
Donghong & & $* * * *$ & .001 & .000 & .001 & .002 & .002 & .000 \\
Haenam & & $* * * *$ & .003 & .003 & .001 & .005 & .003 \\
Sanghyo & & & $* * * *$ & .002 & .002 & .002 & .000 \\
Suak & & & & $* * * *$ & .001 & .002 & .005 \\
Sundol & & & & & $* * * *$ & .001 & .006 \\
$\begin{array}{l}\text { Wando } \\
\text { island }\end{array}$ & & & & & & & $* * * *$ & .005 \\
Youngbul & & & & & & & & $* * * *$ \\
\hline
\end{tabular}


differentiation was the distribution to Jeju island and the island areas of the southern and western coasts as the Ice Age and Melting Age made the seeds increasingly differentiated in Jeju island and Japan's subtropical area south of Tokara Channel, subtropical and Taiwan, but also genetic interchange actively takes place with populations which are distributed far away, for the distribution of seeds are accomplished by birds.

\section{Discussion}

We studied the genetic diversity of eight naturally distributed populations through the same rank enzymes for the purpose of growing and preserving the Dendropanax. That grows in value more and more as a tree that produces golden natural paint and as an ornamental plant. After presuming the genetic variation of eleven genetic loci, five with the same rank enzymes, each average number of allele was 1.4 to 1.7 with the mean of 1.5, and the average of the observed value of heterozygosity $(\mathrm{Ho})$ ranged from 0.075 (Sundol) to 0.123 (Snaghyo) with the mean of 0.100 . The average expected value of heterozygosity $(\mathrm{He}$ ) ranged from 0.075 (Suak, Sundol) to 0.123 (Wando island) with the mean of 0.095 . The diversity in the Suak population was low compared to the other populations, and that of the Wando island population was high. Compared to other tree specimen's genetic diversity this was low. Therefore, from this result, we can presume that genetic diversity was highly decreased, not only because of the differentiation of Dendropanax, but also because of genetic firm with man-made mating.

The populations of Dendropanax has little genetic diversity, compared to the amount of average variation $(A / L: 1.68, P=45.1 \%, H e=0.143$, HAMrICK et al., 1992) of a broad-leaf tree species, and the genetic diversity is more or less high compared to Koelreuteria (LEE et al., 1997), which has limited distribution and is unsustainable, rare species. The group of Dendropanax has the same genetic diversity compared to Abeliophyllum. From these results, according to Ledig and CONKEL (1983), a marginal population has little genetic diversity compared to a central population. And a refugee population during the glacial epoch has decreased genetic diversity because of the bottleneck state. FALK and HoLSINGER (1991) reported that plants species that have limited distribution or are in the state of extinction have little genetic diversity by genetic firm, near-relationship mating.

Especially, Dendropanax, the official material of this study, from the plant's geo-historical point of view, because of species movement caused by the repetition of the Ice Age, differentiated from both Jeju island and subtropical zone of Japan, the south of Tokara Channel (IM, 1992). In addition, in it's ranges from Jeju island, Dendropanax was used without limit as a fuel and an instrument for farming and fishing during Japanese colonial period. As a result most of the native stands were destroyed. Now, it exists isolated with small populations at shrine and on the inaccessible cliff. Genetic diversity has been greatly decreased due to the reason of differentiation and man-made destruction. Finally, because of the reasons given above, the amount of genetic diversity of existing Dendropanax has quite decreased. Therefore, considering the economic value and reduction of distribution range of Dendropanax, we should take some steps to protect the further reduction of genetic diversity.

From the result of Wright's F analysis, we know that the frequency of heterozygote was high compared to the Hardy-Weinberg parallelism frequency, but there was little difference between populations $\left(F_{S T}=0.035\right)$. Nei's cluster analysis of genetic distance should be proper action in order to secure Dendropanax's genetic material and preserve the genetic variation. In other words, recently people are focused on the breed's development because of the value of Dendropanax as an ornamental plant and a golden paint-producing plant. According to the results of this study, because there is not enough genetic diversity, in the future we can't supply a variety of breeding materials. Now is the time to take steps to keep the present genetic diversity. In order to do so, we need to think about the preservation method both inside and outside the actual location and related to the people responsible for carrying it out.

For preservation inside the actual location, because there is no differentiation between populations, several groups which would be various large sizes and easily produce next generations should be set up as the preservation population and be managed collectively by local people. Also, we should think about the preservation methods outside the actual location. After collecting samples from the majority group or preservation population, the samples could be multiplies and preserves at a forest nursery by people committed to their care and growth.

\section{References}

Chapco, W. (1976): An exact test of the Hardy-Weinberg law. Biometrics 32: 183-189.

FALK, D. A. and K. (eds). Holsinger (1991): Genetics and Conservation of Rare Plants. Oxford University Press, New York, USA. 388pp.

HAMrick, J. L., Y. B. Linhart and J. B. Mitton (1979): Relationships between life history characteristics and electrophoretically detectable genetic variation in plants. Ann. Rev. Ecol. Syst. 10: 173-200.

Hamrick, R. J., M. J. W. GodT and S. L. Sherman-Broyles (1992): Factors influencing levels of genetic diversity in woody plant species. New Forests 6: 95-24.

IM, H. T. (1992): Plant geographical study for the plant of Cheju. Kor. Jour. Plant Tax. 22: 219-234.

KIM, J. S., S. W. LEE and J. O. Hyun (1993): Allozyme variation in six native oak species in Korea. Ann. Sci. For. 50(suppl 1): 253s-260s.

KIM, S. H. (1998): Ecology and superior tree selection of Dendropanax morbifera Lev. Ph.D Thesis, Gyeongsang Nat. Univ, Chinju, Korea. 134p.

KIM, S. H., C. S. NA, W. W. KIM, Y. J. KIM and C. H. SHIN (1994): Leaf variation of native Dendropanax morbifera populations in southern Korea. Res. Rep. For. Gen. Inst. 30: $75-84$.

LEDig, F. T. and M. T. ConKel (1983): Gene diversity and genetic structure in a narrow endemic, Torrey pine Pinus torreyana Parry ex Carr. Evolution 37: 79-85. 
LeE, S. W., S. C. KIM, W. W. KIM, S. D. HAN and K. B. Yim (1997): Characteristics of leaf morphological, vegetation and genetic variation in the endemic populations of a rate tree species, Koelreuteria paniculata Laxm. Jour. Kor. For. Soc. 86: 167-176.

LEE, S. W., S. C. KIM and H. S. LEE (1998): Allozyme variation in Abeliophyllum distichum Nakai. an endemic tree species of Korea. Silvae Genetica 47: 294-298.

LEE, S. W., W. W. KIM, B. C. LeE, Y. Y. KIM and S. C. KIM (1995): Genetic variation of acorn production stands in Quercus acutissima and Q. variabilis. Kor. Jour. Breed. 27: 345-358.

LesicA, P., R. F. Leary, F. W. Allendorf and D. E. BilderBACK (1995): Lack of genetic diversity within and among populations of an endangered plant, Howellia aquatilis. Conservation Biology 2: 275-282.

LOVELESS, M. D. and J. L. HAMrICK (1984): Ecological determinants of genetic structure in plant populations. Ann. Rev. Ecol. Syst. 15: 65-95.

NEL, M. (1978): Estimation of average heterozygosity and genetic distance from a small number of individuals. Genetics 89: 583-590.
Sneath, D. L. and R. R. Sokal (1973): Numerical Taxonomy. WH Freeman and Co., San Francisco, USA. 573pp.

SoKAL, R. R. and F. J. RoHLF (1981): Biometrics. $2^{\text {nd }}$ ed. WH Freeman and Co., San Francisco, USA. 859p.

SwOFFoRD, D. L. and R. B. SELANDER (1989): BIOSYS-1: a computer program for the analysis of allelic variation in population genetics and biochemical systematics. Release 1.7. Illinois Natural History Survey.

Waller, D. M., D. M. O'Malley and S. C. GaWler (1987): Genetic variation in the extreme endemic Pedicularis furbishiae (Scrophulariaceae). Conservation Biology 1: $335-340$.

WeEden, N. F. and J. F. Wendel (1989): Genetics of plant isozymes. In: Isozymes in Plant Biology. Edited by D. E. Soltis and P. S. Soltis. Dioscorides Press. Portland, Oregon, USA. pp.46-72.

Won, B. O. (1981): Illustrated Flora and Fauna of Korea Vol. 25 Avifauna. Ministry of Education.

WRIGHT, S. (1978): Evolution and the genetics of population. variability within and among natural population. University of Chicago Press. Chicago, USA.

\title{
Comparison of Phenotype and Combined Index Selection at Optimal Breeding Population Size Considering Gain and Gene Diversity
}

\author{
By H. Li ${ }^{1) * *)}$ and D. LINDGREN ${ }^{2)}$
}

(Received $1^{\text {st }}$ July 2005)

\begin{abstract}
A breeding program was simulated in this study. Two alternative ways of selecting the breeding population for the following generation was compared. Phenotypic selection, which means to select just on the individual performance, and combined index selection, which means selection on predicted breeding value for each individual obtained by weighting family average and individual phenotype, were compared. The plant number (testing resource) and gene diversity (status number, $\mathrm{Ns}$ ) were kept constant, but the breeding population size was variable and chosen for maximizing gain for the particular breeding scenario. At low and medium heritability phenotypic selection was inferior to combined index selection. Only when heritability was high phenotypic selection was as efficient (generation 1) as or more efficient (generation 5) than combined index selection. This contrasts to earlier studies done under constant breeding population size, where selection methods appeared similar. The advantage in gain of combined index selection is usually at a larger breeding popula-

1) College of Forest Resources and Environments, Nanjing Forestry University, Nanjing 210037, P. R. China.

$\left.{ }^{2}\right)$ Department of Forest Genetics and Plant Physiology, Swedish University of Agricultural Sciences, S-901 83 Umeå, Sweden. Email: Dag.Lindgren@genfys.slu.se.

*) Corresponding Author: HuOGEN LI, Tel: 0086-25-85428731, Fax: 0086-25-85427412, email: hgli@njfu.edu.cn.
\end{abstract}

tion size. At limited heritability and breeding population size the difference is considerable. When breeding population size was kept rather small $(<100)$, and the heritability limited, combined index selection can result in slightly higher gain than phenotypic selection at the same gene diversity, but this was at the cost of a much larger breeding population. Phenotypic selection and combined index selection appears as rather similar for many cases in this simple model used in this study. Considering other advantages with phenotypic selection, it may often be regarded as a competitive alternative.

Key words: heritability, genetic gain, status number, gene diversity, breeding population size, selection efficiency.

\section{Introduction}

Genetic gain and gene diversity are two goals which plants breeders want to combine, it means that a compromise between these two goals has to be made. Phenotypic selection (PS, mass selection) is based on individual performance only. Combined index selection (CIS) means selection based on an index combining individual values with family averages weighting the two sources of information to maximise the correlations between the index and the true breeding values of the individuals, and it maximizes genetic gain (FALCONER, 1989). Phenotypic selection (PS) is a classical method, it is very sim- 